\title{
Ximelagatran prevented secondary venous thromboembolism
}

Schulman S, Wåhlander K, Lundström T, et al. Secondary prevention of venous thromboembolism with the oral direct thrombin inhibitor ximelagatran. N Engl J Med 2003;349:1713-21.

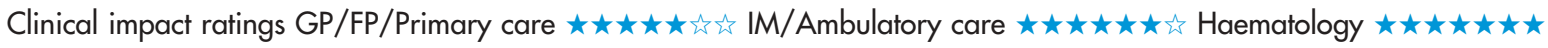

What is the long term efficacy and safety of ximelagatran after 6 months of standard anticoagulant therapy for secondary prevention of venous thromboembolism (VTE)?

\section{METHODS}

L

Design: randomised placebo controlled trial (Thrombin Inhibito in Venous Thromboembolism [THRIVE III]).

Allocation: concealed.*

Blinding: blinded (clinicians, patients, \{data collectors, outcome assessors, and data analysts\}†).

Follow up period: 18 months.

Setting 142 centres in 18 countries.

Patients 1233 patients who were $\geqslant 18$ years of age with symptomatic, objectively confirmed deep venous thrombosis (DVT) or pulmonary embolism (PE) and had received anticoagulant therapy for 6 months with no recurrent VTE event. Exclusion criteria: indication for continuous anticoagulan therapy, haemoglobin level $<9.0 \mathrm{~g} / \mathrm{dl}$, platelet count $<90000 /$ $\mathrm{mm}^{3}$, pregnancy, lactation, expected survival $<18$ months, renal impairment, clinically important liver disease, or persistent elevation of the aminotransferase level $>3$ times the upper limit of normal.

D Intervention: twice daily ximelagatran, $24 \mathrm{mg}(\mathrm{n}=612)$, or placebo $(n=611)$ for 18 months. All patients discontinued anticoagulant therapy but did not begin study treatment until the international normalised ratio (INR) was $<1.5$.

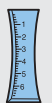

Outcomes: VTE (recurrent DVT and PE), major and minor bleeding, and all cause mortality.

Patient follow up: 1223 patients (99\%) (mean age 57 y, 53\% men) were included in the intention to treat analysis.

*See glossary.

†Information provided by author.

\section{MAIN RESULTS}

Fewer patients who received ximelagatran had recurrent VTE events than did patients who received placebo (table). Groups did not differ for major or minor bleeding or for all cause mortality (table).

\section{CONCLUSION}

In patients with deep venous thrombosis or pulmonary embolism receiving standard anticoagulant therapy for 6 months, ximelagatran reduced recurrent venous thromboembolism and did not increase bleeding.

\section{Abstract and commentary also appear in ACP Journal Club.}

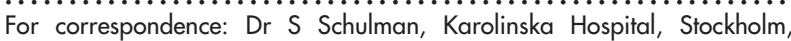
Sweden. sam.schulman@ks.se

Source of funding: AstraZeneca Research and Development.

\section{Commentary - continued from previous page}

7 he optimal long term treatment of patients who present with unprovoked (or idiopathic) VTE is controversial. 15\%-30\% of patients with idiopathic VTE will have recurrent VTE in the first year after 3-6 months of anticoagulation. Prolonging the duration of anticoagulation beyond 3-6 months may delay recurrences while exposing patients to the haemorrhagic risk associated with extended anticoagulation. The possibility that a lower intensity warfarin regimen (INR 1.5-1.9) would allow safer anticoagulation without compromising efficacy ${ }^{2}$ was trumped by the results of another study that showed that conventional intensity anticoagulation (INR 2.0-3.0) has better efficacy than a lower intensity regimen. ${ }^{3}$ The results of the trial by Schulman et al show that long term ximelagatran therapy, administered orally in a fixed dose and without laboratory monitoring, is effective for preventing recurrent VTE in patients who received 6 months of conventional anticoagulant therapy and is not associated with an increased haemorrhagic risk.

However, the extent to which ximelagatran prevented recurrent VTE was not different from that of oral anticoagulants in the many trials that addressed their benefit. Furthermore, the apparent lack of haemorrhagic potential may have been because of the unusually high rate of bleeding in patients who received placebo. Finally, in about $6 \%$ of patients, aminotransferase concentrations increased to $>3$ times the upper limit of normal. Additional research is required to identify the optimal strategy of long term anticoagulation in patients with idiopathic VTE. There is the potential that disease recurrence can be predicted on an individual basis after 3-6 months of conventional therapy if venous ultrasonography shows persistent abnormalities or D dimer levels are elevated. ${ }^{4}$

Paolo Prandoni, MD University of Padua Padua, Italy

1 Eriksson BI, Agnelli G, Cohen AT, et al. J Thromb Haemost 2003;1:2490-6.

2 Ridker PM, Goldhaber SZ, Danielson E, et al. N Engl J Med 2003;348:1425-34.

3 Kearon C, Ginsberg JS, Kovacs MJ, et al. N Engl J Med 2003;349:631-9.

4 Prandoni $\mathrm{P}$, Lensing $\mathrm{AW}$, Prins $\mathrm{MH}$, et al. Ann Intern Med

2002; 137:955-60.

5 Palareti G, Legnani C, Cosmi B, et al. Circulation 2003;108:313-8.
Ximelagatran $v$ placebo for secondary prevention of venous thromboembolism (VTE) at 18 months*

\begin{tabular}{lccll}
\hline Outcomes & Ximelagatran & Placebo & RRR (95\% CI) & NNT (CI) \\
\hline VTE & $2.8 \%$ & $12.6 \%$ & $\begin{array}{l}83 \% \\
(69 \text { to } 90)\end{array}$ & 10 (9 to 12) \\
$\begin{array}{l}\text { All cause } \\
\text { mortality }\end{array}$ & $1.1 \%$ & $1.4 \%$ & $\begin{array}{l}17 \% \\
(-143 \text { to } 72)\end{array}$ & Not significant \\
$\begin{array}{l}\text { Major } \\
\text { bleeding }\end{array}$ & $1.1 \%$ & $1.3 \%$ & $\begin{array}{l}16 \% \\
(-65 \text { to } 273)\end{array}$ & Not significant \\
\hline & & RRI (CI) & NNH \\
\hline $\begin{array}{l}\text { Major and } \\
\text { minor } \\
\text { bleeding }\end{array}$ & $23.9 \%$ & $21.0 \%$ & $\begin{array}{l}16 \% \\
(-6 \text { to } 44)\end{array}$ & Not significant \\
\hline
\end{tabular}

*Abbreviations defined in glossary; RRR, RRI, NNT, NNH, and Cl calculated using Cox proportional hazards ratio in article. 